\section{Analysis of factors related to maternal health in female workers in the industrial area of Sidoarjo, Indonesia}

\author{
Firman Suryadi Rahman, Tri Martiana \\ Faculty of Public Health, Universitas \\ Airlangga, Surabaya, Indonesia
}

\begin{abstract}
Female workers are often exposed to various risk factors that potentially threaten their health, including reproductive health. One of the reproductive problems for female worker is a pregnancy disorder. Disorders during pregnancy can result in the occurrence of infant mortality and maternal death. The aim of this study was to analyze the factors associated with maternal health in female workers in Sidoarjo Industrial area. The study was a cross-sectional study with 388 chosen by simple random sampling. Data was analyzed using chi-square. The results showed that there was a correlation between pregnancy disorders and maternal education $(\mathrm{p}=0.05)$, work shift $(\mathrm{p}=0.036)$, dust $(\mathrm{p}=0.04)$, vibration $(\mathrm{p}=0.009)$. Maternal and child health is influenced by internal factors such as education level and external factors in the form of work shifts, hazards dust and vibration in the company environment. Industrial management needs to provide health education to reduce the risks of pregnancy disorders.
\end{abstract}

\section{Introduction}

Maternal and Child Health is one component of health that needs to be considered. World Health Organization (2016) data states that there are around 830 pregnant women died every day. In Indonesia, the maternal mortality rate (MMR) is still at 305 per 100,000 live births. MMR can be used to assess the quality of health services for pregnant women both in terms of accessibility and quality. Maternal health services that need to be considered include maternal health services, childbirth assistance by health workers trained in health facilities, post-natal care for mothers and babies for special care in the event of complications, ease of obtaining maternity leave and family planning services.

The number of workers in East Java Province in 2017 was $20,099,220$. The number of male workers was $11,947,824$, while that of female workers was $8,151,396 .{ }^{1}$ This number was $40.56 \%$ of the total workforce in Indonesia. In recent years, the number of female workers in Indonesia had increased. In 2017, the number of female workers in Indonesia reached $38.2 \%$ compare to that of male worker. ${ }^{2}$

Each country has its own protection for female workers against hazard in working environment. In Indonesia, the law provides some special protection for female workers such as permission to take a leave during their first and second day of menstruation, permission to rest before and after giving birth, restriction from working at night and working over 40 hours a week (The Republic of Indonesia's Labor Law No. 13 Year 2003). ${ }^{2}$ However, in reality many female workers still have to work over 40 hours per week and it is difficult to get their rights to take a maternity leave during the pregnancy. 3,4

Female workers need to be guarded and protected from workplace hazards especially when they are in menstrual period, pregnancy period, and breastfeeding period. ${ }^{5}$ The hazards in work environment may cause various disorders such as menstrual disorders and pregnancy disorders among the female workers. ${ }^{6}$ It is important to protect female workers during their pregnancy states, so that they avoid the consequences health risks for both the workers and their babies. The objective of this study is to analyze the factors associated to maternal Health in female workers in Sidoarjo Industrial area.

\section{Materials and Methods}

This study is an observational study with a cross sectional study conducted in Sidoarjo industrial area, Indonesia with female workers. The total sample of the study was 500 female workers but those who attended the study to the end were 388 female workers. The study was conducted in September-November 2017. The dependent variable of careful maternal health is the occurrence of disorders during pregnancy, while in children is the provision of exclusive breastfeeding. Independent variables include maternal education, BMI, work shifts, length of work, hazard in the work environment. Data collection was done using a questionnaire with interview methods to research respondents. Data was analyzed using chi-square analysis.

\section{Results}

\section{Pregnancy Disorders}

Table 1 shows female workers in the
Correspondence: Tri Martiana, Occupational Health and Safety Department, Faculty of Public Health, Universitas Airlangga, Jl. Mulyorejo, Surabaya, Jawa Timur 60115, Indonesia.

Tel. +62.31 .5920948 - Fax: +62.31 .5924618$

E-mail: tri.martiana@fkm.unair.ac.id

Key words: female workers, pregnancy disorders, maternal health, hazard.

Acknowledgments: the authors would like to thank all research and field team for helping this study.

Contributions: the authors contributed equally.

Conflict of interests: the authors declare that there is no potential conflict of interests regarding the publication of this article.

Funding: none.

Clinical trials: this research has been approved by research ethics committee of Faculty of Public Health, Universitas Airlangga Indonesia.

Conference presentation: part of this paper was presented at the $3^{\text {rd }}$ International Symposium of Public Health, 2018 October 31 - November 1, Universitas Airlangga, Surabaya, Indonesia.

Dedication: the article is dedicated to Faculty of Public Health, Universitas Airlangga.

Received for publication: 28 July 2019

Revision received: 9 September 2019.

Accepted for publication: 15 October 2019.

This work is licensed under a Creative Commons Attribution NonCommercial 4.0 License (CC BY-NC 4.0).

(C) Copyright: the Author(s), 2019

Licensee PAGEPress, Italy

Journal of Public Health in Africa 2019; 10(s1):1179 doi:10.4081/jphia.2019.1179

Sidoarjo area industry who experienced a disruption during pregnancy at $35.6 \%$.

\section{The Characteristics of Research Respondents in Industrial Area of Sidoarjo}

Table 2 shows that the majority of female workers' last level of education in the Sidoarjo area industry is high school which is equal to $46.1 \%$. Most BMIs was categorized normal $(45.4 \%)$, most have worked in the Sidoarjo area industry for 1120 years $(48.5 \%)$, most have worked shifts $(84.3 \%)$ and most are married within the ages of $17-25(72.7 \%)$. 


\section{Hazard}

Table 3 shows that the majority of female workers in the Sidoarjo industrial area are exposed to noise $(70.1 \%)$, experience heat as much as $80.7 \%$, exposure to dust as much as $248 \%$, exposure to pungent odors as much as $119 \%$ and jobs that monotonous at $66.5 \%$.

\section{Relationship between Independent Variables and Variables in Pregnancy Disorders}

Table 4 shows that the variables of education, work shifts, dust and vibration are related to pregnancy disorders in female workers in the Sidoarjo area industry (p value $<0.05$ ).

\section{Discussion}

\section{Pregnancy disorders}

A woman who works will run the risk of developing ruptured membranes, premature birth and difficulties when giving birth compared to housewives. Female workers who work for a long duration (more than 40 working hours/week) will be at risk for some pregnancy problems, women generally pay less attention to the nutrients that need to be consumed during pregnancy. 7,8

During pregnancy, female workers need some special treatment and are vulnerable to hazards dwarfed by embryonic development, so that women workers are more vulnerable to dangerous agents if it is compared to non-working mothers, women, women are not suitable for certain jobs, pregnancy will reduce women's ability to survive several employment factors. ${ }^{9,10}$ The Indonesian Government provides special protection for women workers. The protection is regulated in law. The rights to be protected are the protection of women's work, menstruation leave, maternity leave, childbirth and fallout, the opportunity to breastfeed a child, and the elimination of the difference in need for female labor.

The Indonesian government provides protection to prohibit female workers from working at night, but it is still permissible if there is a need for female workers with social, technical and economic reasons. In addition, female workers are also entitled to apply for leave on the first and second day of their menstruation period. Maternity leave can also be obtained by female workers at one and a half months before and after giving birth. This is the commitment of the Indonesian government to protect the health of pregnant women, especially for female workers who have more risk factors than housewives.

\section{Education}

The level of education of pregnant women will affect mother's knowledge about antenatal care that needs to be done when the mother is pregnant. Better education will encourage a mother to be able to do an examination, choose nutritious food and do antenatal care that will prevent pregnancy problems. Good education will encourage a mother to be able to maintain a good pregnancy. A mother with a good education will have good knowledge, so that she can choose and avoid good behavior for obstetric health. ${ }^{2}$

Table 1. Distribution of Respondents According to Pregnancy Disorders.

\begin{tabular}{lcc}
\hline Experiencing Disorders & Total & Percentage (\%) \\
Yes & 138 & 35.6 \\
No & 250 & 64.4 \\
\hline
\end{tabular}

Table 2. Characteristics of Respondents in the Industrial Area of Sidoarjo.

\begin{tabular}{lcc} 
Variable & Total & Percentage (\%) \\
Education & & 0.3 \\
$\quad$ Not Got Education & 1 & 10.1 \\
Elementary & 39 & 37.4 \\
Junior high School & 145 & 46.1 \\
Senior high School & 179 & 6.2 \\
$\quad$ Universities & 24 & \\
BMI & & 35.8 \\
Fat & 139 & 2.5 \\
Thin & 10 & 45.4 \\
Normal & 176 & 16.0 \\
Obesity & 62 & 3.0 \\
Very Thin & 1 & \\
Years of Service & & 22.4 \\
$0-10$ years & 87 & 48.5 \\
11-20 years & 188 & 26.5 \\
$21-30$ years & 103 & 2.6 \\
$31-40$ years & 10 & \\
Work Shift & & 84.3 \\
Yes & 327 & 15.7 \\
No & 61 & \\
\hline Age Married (Years Old) & & 0.3 \\
Not remember & 1 & 5.7 \\
$<17$ & 22 & 72.7 \\
17-25 & 282 & 19.8 \\
$26-34$ & 67 & 1.5 \\
$>34$ & &
\end{tabular}

Table 3. Distribution of respondents by Hazard in the Work Environment in Industrial area of Sidoarjo.

\begin{tabular}{lcc} 
Variable & Total & Percentage (\%) \\
Noise & & \\
$\quad$ Yes & 272 & 70.1 \\
$\quad$ No & 116 & 29.9 \\
Heat & & \\
$\quad$ Yes & 313 & 80.7 \\
$\quad$ No & 116 & 19.3 \\
\hline Dust Exposure & & \\
$\quad$ Yes & 248 & 63.9 \\
$\quad$ No & 140 & 36.1 \\
Odor stingin & & \\
$\quad$ Yes & 119 & 30.7 \\
$\quad$ No & 269 & 69.3 \\
\hline Monotone & & 66.5 \\
$\quad$ Yes & 258 & 33.5 \\
$\quad$ No & 130 & \\
\hline
\end{tabular}




\section{Work Shift}

One that affects the health of pregnant women and infants is work shifts in the work environment. Gamble et.al stated that reproductive health issues are associated with working nights or rotating shifts. 10 For example, shift work has been associated with an increased risk of irregular menstrual cycles, endometriosis, infertility, miscarriage, low birth weight or pre-term delivery, and reduced incidence of breastfeeding. In addition, work shift can affect circadian rhythms that can affect the quality of sleep and health of female workers. Irregular work shifts will lead to pregnancy disorders and developmental disorders of infants after birth. ${ }^{11}$

The results showed that female workers with night shifts increased the risk of cancer, cardiovascular disease, diabetes, metabolic syndromes and reproductive disorders when compared with female workers with traditional working hours. Meanwhile, the period of work and work attitude did not affect the reproductive health disorders of female workers. The results were in line with the study conducted by Zhu, Hjollund, Olsen who stated that there is a correlation between shift work and the incidence of pregnancy disorders on female workers. ${ }^{12}$ The Women who work in the evening and night shifts will tend to experience prematurity-like disorders such as prematurely born and impaired fetal growth. According to Zhu, Hjollund, Olsen, fixed night work had a high risk of post term birth (odds ratio, 1.35; 95\% CI, 1.01-1.79); fixed evening work had a high risk of full-term low birth weight (odds ratio, 1.80; 95\% CI, 1.102.94); and shift work as a group showed a slight excess of small-for-gestational-age babies (odds ratio, 1.09; 95\% CI, 1.001.18). ${ }^{12}$

Table 4. Relationship between Independent Variables with Pregnancy Disorders in Women Workers in the Work Environment in the Industrial Area of Sidoarjo $(\mathbf{n}=388)$.

\begin{tabular}{lc} 
Variables & p-value \\
Education Area & $0.050^{*}$ \\
BMI & 0.407 \\
\hline Work Duration & 0.178 \\
Shift Work & $0.025^{*}$ \\
\hline Age Married & 0.138 \\
Noisy & 0.147 \\
\hline Heat & 0.073 \\
Dust Exposure & $0.031^{*}$ \\
\hline Stinging Odor & 0.125 \\
Vibration & $0.007^{*}$ \\
\hline Monotone & 0.161 \\
\hline
\end{tabular}

Shift work and irregular work affect the system work in the body. Work shift changes the circadian rhythm that affects the ovulatory cycle and impacts on irregular menstruation. ${ }^{13}$ It also affects the process of pregnancy that occurs. Working women need to be given suitable or non-shifts working hours and avoid work shifts that aggravate their work. ${ }^{14}$ This needs to be implemented for female workers to avoid any pregnancy disruption that can occur. A good working time for pregnant women is between 07.00 and 18.00 and not more than 40 hours a week. ${ }^{15}$

Based on the reproductive health manual in the workplace published by Ministry of Health Republic of Indonesia, ${ }^{16}$ work rotation and work shifts can cause stress to female workers. This can cause menstrual disorders and libido disorders. The more irregular work shift they have, the greater influence on the circulatory system they experience. Thus, job rotation or division of work shifts needs to be done by considering the health effects on female workers. ${ }^{17,18}$

Female workers who work in the evening and at night shifts will be at risk of pregnancy disorders and miscarriage compared to those who work at normal working hours. Shift work rules and irregular working hours result in fetal miscarriage. Female workers working at night shifts during the first 20 weeks of pregnancy are particularly vulnerable and at risk of HDP (Hypersensitive Disorders of Pregnancy). ${ }^{19,20}$ This risk will double if they return to work at the night shift the next day. If a female worker gets a night shift, the company needs to provide sufficient rest time for the female workers to avoid the occurrence of HDP. The risk of female workers working on night shifts will increase if they have BMI $\geq 30 \mathrm{~kg} / \mathrm{m} 2 .^{21,22}$

\section{Dust}

The results of the study showed a significant relationship between exposure to dust and pregnancy disorders in female workers in Sidoarjo area. This is in line with the research conducted by Shih et al, namely dust exposure can cause an adverse pregnancy outcome and child mortality. The presence of dust exposure can affect fetal brain development and cognitive function development in infants. Other research results also found that exposure to dust in the early trimester can affect the development of infants at the beginning of their lifetime. Chen Lee states that dust exposure that occurs during pregnancy can cause gestational hypertension, preterm delivery, and small for gestational age. ${ }^{23}$

\section{Vibration}

Vibration in the workplace can cause various effects for workers, especially female workers who are pregnant. Workers who are exposed to vibrations continuously can experience neurological, musculoskeletal and vascular problems. Meanwhile for Whole Body Vibration can cause Hypertrophy in young people but it is very important to avoid those who are weak and unhealthy. WBV can also disrupt the reproductive organ system in women. If this hazardous hazard occurs during the pregnancy process, eating can result in a disruption in pregnancy. Thus, women workers who are pregnant need to be avoided from the presence of vibrations, especially WBV in the work environment. ${ }^{24}$ The results of the study also state that during pregnancy a vibration event is one of the causes of pregnancy disorders and even miscarriages. According to Mc Donald et al., Vibration correlates with low birth weight, pretern labor, and stillbirth. In addition, the exposure to vibration can increase the risk of miscarriage. Long exposure to vibration will not cause fatal fetal abnormalities (abnormalities), but can increase the risk of giving birth to premature babies or low birth weight. ${ }^{25}$

\section{Conclusions}

Maternal and child health is influenced by internal factors such as education level and external factors in the form of work shifts, hazards dust and vibration in the company environment. The Company needs to provide health education about $\mathrm{MCH}$ to female workers and the company needs to control the existing hazard.

\section{References}

1. World Bank. Labor Force data. ILO Data Sheet for Indonesia. Jakarta; World Bank; 2017.

2. Statistic Indonesia. Workforce in Indonesia. Jakarta: BPS Press; 2017.

3. Johnson CY, Rocheleau CM, Lawson $\mathrm{CC}$, et al. Factors affecting workforce participation and healthy worker biases in U.S. women and men. Ann Epidemiol 2017;27(9):558-562.

4. Gesser-Edelsburg A, Shir-Raz Y, Hayek $S$, et al. Despite awareness of recommendations, why do health care workers not immunize pregnant women? Am J Infect Control 2017;45(4):436-9.

5. Rim K-T. Reproductive Toxic Chemicals at Work and Efforts to Protect Workers' Health: A Literature 
Review. Saf Health Work 2017;8(2):143-50.

6. Grajewski B, Rocheleau CM, Lawson $\mathrm{CC}$, et al. "Will my work affect my pregnancy?" Resources for anticipating and answering patients' questions. Am J Obstet Gynecol 2016;214(5):597-602.

7. Kervezee L, Shechter A, Boivin DB. Impact of Shift Work on the Circadian Timing System and Health in Women. Sleep Med Clin. 2018;13(3):295-306.

8. Gamble KL, Resuehr D, Johnson CH. Shift Work and Circadian Dysregulation of Reproduction. Front Endocrinol (Lausanne) 2013;4:92.

9. Wright KP, Bogan RK, Wyatt JK. Shift work and the assessment and management of shift work disorder (SWD). Sleep Med Rev 2013;17(1):41-54.

10. Zhu JL, Hjollund NH, Olsen J. Shift work, duration of pregnancy, and birth weight:: The National Birth Cohort in Denmark. Am J Obstet Gynecol 2004;191(1):285-91.

11. Dumont M, Paquet J. Progressive decrease of melatonin production over consecutive days of simulated night work. Chronobiol Int. 2014;31(10): 1231-8.

12. Lunn RM, Blask DE, Coogan AN, et al. Health consequences of electric lighting practices in the modern world: A report on the National Toxicology Program's workshop on shift work at night, artificial light at night, and circadian disruption. Sci Total Environ. 2017;607608:1073-84.

13. Straif K, Baan R, Grosse Y, Secretan B, et al. Carcinogenicity of shift-work, painting, and fire-fighting. Lancet Oncol. 2007;8(12):1065-6.

14. Ministry of Health RI. Health reproduction for female worker. Jakarta: $\mathrm{MoH}$ Press; 2009.

15. Wickwire EM, Geiger-Brown J, Scharf SM, et al. Shift Work and Shift Work Sleep Disorder: Clinical and Organizational Perspectives. Chest 2017;151(5):1156-72.

16. Boivin DB, Boudreau P. Impacts of shift work on sleep and circadian rhythms. Pathol Biol. 2014;62(5):292301.

17. Figueiro MG, Steverson B, Heerwagen $\mathrm{J}$, et al. The impact of daytime light exposures on sleep and mood in office workers. Sleep Heal. 2017;3(3):204-15.

18. Vallières A, Azaiez A, Moreau V, et al. Insomnia in shift work. Sleep Med. 2014;15(12):1440-8.

19. Stevens RG, Hansen J, Costa G, et al. Considerations of circadian impact for defining 'shift work' in cancer studies: IARC Working Group Report. Occup Environ Med. 2011;68(2):154-162.

20. Hammer P, Flachs E, Specht I, et al.
Night work and hypertensive disorders of pregnancy: a national register-based cohort study. Scand J Work Environ Health 2018;44(4):403-13.

21. Shih YH, Islam T, Hore SK, et al. Association between prenatal arsenic exposure with adverse pregnancy outcome and child mortality. Environ Research 2017;158;456-461.

22. Li Z, Chen L, Li M, et al. Prenatal exposure to sand and dust stroms and children's cognitive function in China. Lancet Planet Health 2018;2(5):214222.

23. Renzetti S, Just AC, Burris HH, et al. The association of lead exposure during pregnancy and childhood anthropometry in the Mexican progress cohort. Environment Research 2017;152;226232.

24. McDonald AD, McDonald JC, Armstrong B, et al. Fetal death and work in pregnancy. $\mathrm{Br} \mathrm{J}$ Ind Med. 1988;45(3):148-157.

25. Safety Services Office. New and Expectant Mothers at Work (Guidance for University Departments and Functions) 2015. Available from: https://www2.le.ac.uk/offices/safetyservices/documents/pdfs/mothers.pdf. Accessed on: 11 October 2018. 